\title{
Monitoring climate variability on the Antarctic Peninsula by means of observations of the snow cover
}

\author{
Christoph Schneider \\ Department of Physical Geography, University of Freiburg, Werderring 4, D-79085 Freiburg, Germany
}

\begin{abstract}
The glaciers of the Antarctic Peninsula are believed to react rapidly to climatic fluctuations. Thus it is of great interest to find methods for monitoring regional climate variability in this region. Two small glaciers on the Antarctic Peninsula were chosen to monitor the accumulation and ablation pattern of the snow cover in respect to climate variations. During two summer seasons, synthetic aperture radar pulse-repetition interval images from the European ERS-l active microwave satellite instrument were collected. Simultaneously, micro-meteorological measurements with simple automatic weather stations were carried out at three locations on the glaciers. Energy available for snowmelt was computed using the bulk transfer equations. Incorporating a digital terrain model and a model for shortwave irradiance, estimates of the energy available for melt were then calculated for the entire glaciers. The resulting time series of spatially distributed information on available energy can be used to separate periods and areas with snowmelt from periods and areas with completely frozen snow cover. The same separation can be achieved from the ERS-1 imagery. Integrating both the remote-sensing technique and the ground observations, it may be possible to establish a combined method to monitor the effects of weather patterns on a seasonal basis.
\end{abstract}

\section{INTRODUCTION}

In recent years, evidence of changes in the regional climatology of the area of the Antarctic Peninsula has been collected using different approaches. Vaughan and Doake (1996) reported the rapid disintegration of ice shelves in the warmer parts of the peninsula, especially on the west coast and in the north. Peel (1992) reported that core studies at two sites in Palmer Land revealed an increase in precipitation. Wunderle (1996b) calculated warming trends between $0.028^{\circ} \mathrm{Ca}^{-1}$ (South Orkneys) and $0.265^{\circ} \mathrm{Ca}^{-1}$ (Adelaide Island) for different stations on the west side of the Antarctic Peninsula. Although statistically not significant, these findings are backed by similar reports from Morris and Vaughan (1992) and Smith and others (1996). The representation of the Antarctic Peninsula in global circulation models (GCMs) is without much detail, due to the small extent from east to west and the high mountain ridge running from north to south. Therefore, predictions of climate change based on GCMs are very uncertain when evaluated for this region. However, all GCMs reveal major changes during summer in the.vicinity of the northward sea-ice border (Schlesinger, 1993). On the west coast of the Antarctic Peninsula, this area coincides with Marguerite Bay, which is located at the transition from a maritime sub-polar climate to a more continental polar climate.

Since glacial systems in this region are much smaller than in continental Antarctica, changes attributed to climate change may be more easily detected than elsewhere in Antarctica. Nevertheless, based on formulations proposed by Paterson (1994), the estimated response time of the glacial systems is of the order of decades. Surface velocities are estimated to be approximately $100-150 \mathrm{~m} \mathrm{a}^{-1}$, as measured with a differential global positioning system (GPS), and with measurements of the displacement of corner reflectors in European remote-sensing satellite (ERS) scenes of the two glaciers investigated in consecutive years. On this assumption, it would take about 50 years for changes in the accumulation and ablation pattern to be propagated halfway down the glacier to the ice barrier. Hence, short-term variations can be monitored, not from glacier behaviour itself, but by monitoring the snow cover, which reflects changes in actual meteorological conditions. The snow cover can be seen as an archive of seasonal meteorological conditions, since snow metamorphism and layering of the snowpack is controlled by temperature, radiation, humidity and wind. However, the spacing of meteorological observations is coarse, with only about ten stations or automatic weather stations (AWSs) being run permanently on the Antarctic Peninsula. For these reasons it would be desirable to have a method of monitoring seasonal meteorological variability and interannual trends which uses a combination of point measurements backed by spatial approaches.

Remote-sensing techniques contribute spatially distributed information to the time series derived from ground measurements. In particular, space-borne synthetic aperture radar (SAR) systems such as ERS, J-ERS and RADARSAT deliver imagery independent of daylight and cloud coverage, which is of major importance in polar environments. Furthermore, the information in the images is due not only to surface scattering of the radiation, but also to volume scattering from the snowpack (Ulaby and others, 1982). Since the dielectric properties of liquid water are very different from those of ice grains or snow crystals, even small amounts of liquid water in the snow cover are detectable by means of radar imagery. Backscatter intensities as 


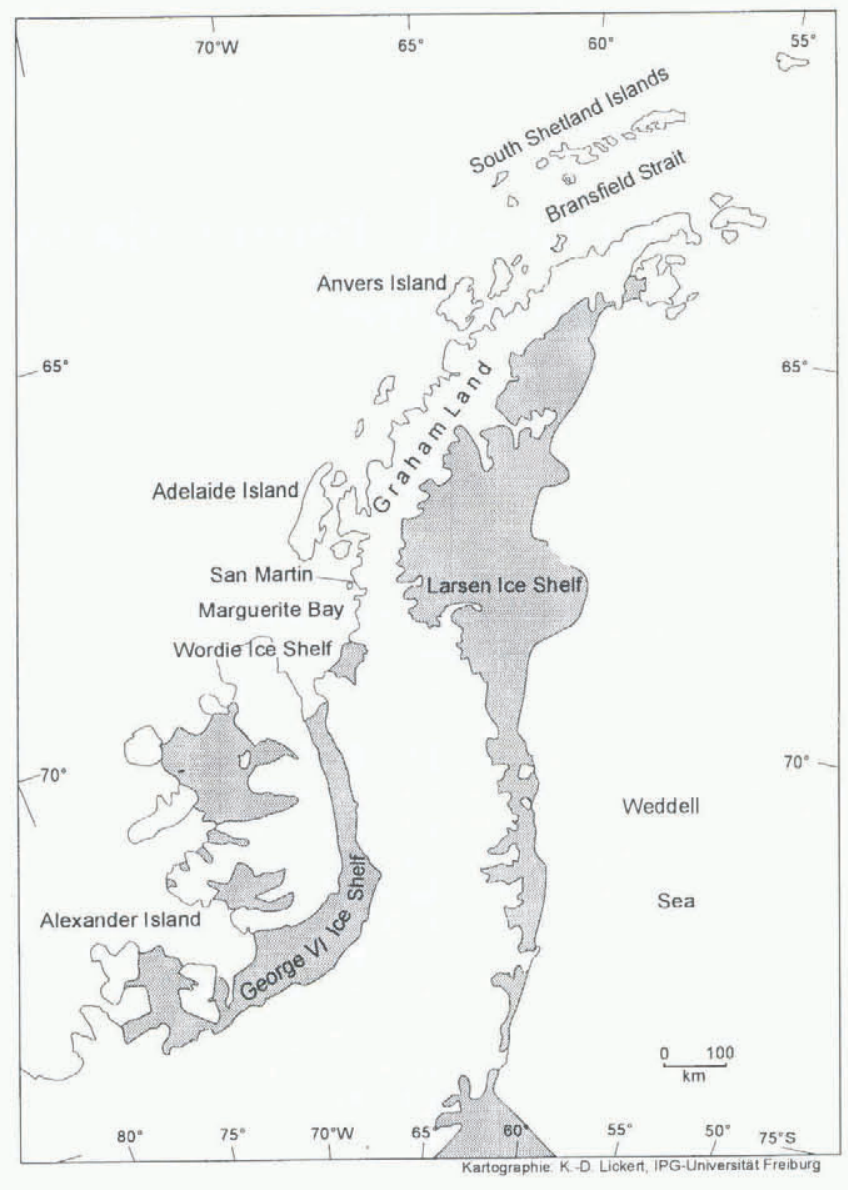

Fig. 1. Map of the Antarctic Peninsula. The area of investigation is located in the vicinity of the Argentinian research base, San Martin.

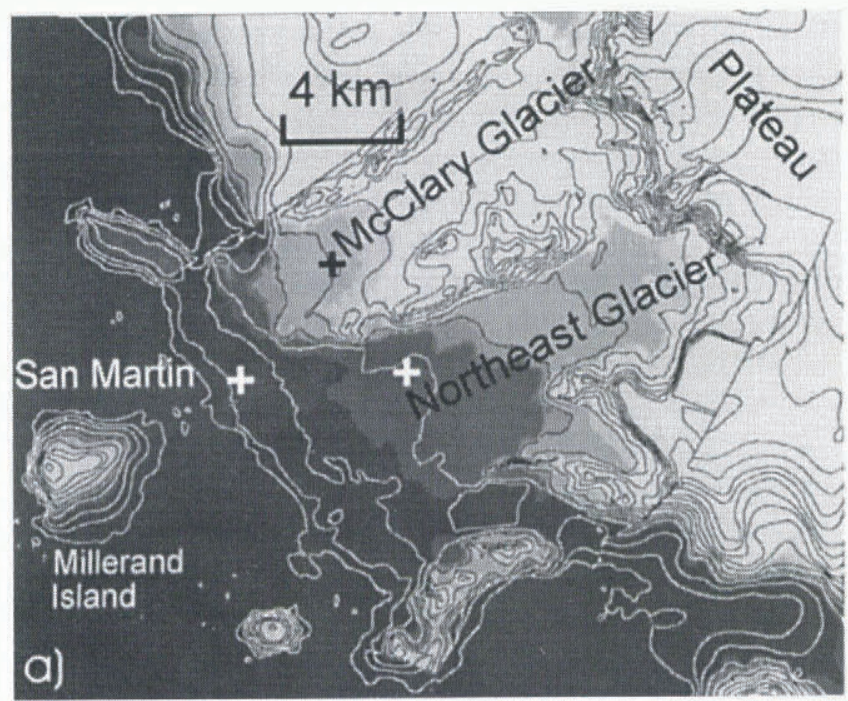

derived from ERS-1/-2 pulse-repetition interval (PRI) images of melting snow surfaces show differences in the calculated backscatter intensities of at least $-15 \mathrm{~dB}$ as compared to completely frozen snow covers in the percolation zone of the Antarctic Peninsula (Wunderle, 1996a; Schneider and others, 1997). Consequently, spatial and altitudinal variations in the transition from wet-snow conditions to frozen snow cover in the percolation zone on glaciers can be monitored by employing time series of ERS-1/-2 imagery. Trends derived from temporal and spatial changes in the location of the transition can than be attributed to changes in regional climatology. In order to develop this method, we compare the remote-sensing data with the spatial distribution of the wet-snow zone as modelled from energy-balance estimates derived from AWS recordings on the glaciers.

\section{AREA OF INVESTIGATION}

To develop and test the methodology outlined above, two glaciers located near $68^{\circ} \mathrm{S}, 67^{\circ} \mathrm{W}$ on the west coast of the Antarctic Peninsula were selected (Fig. 1). The glaciers form a joined ice barrier facing west. The area (Fig. 2a) is accessible by a snow ramp from the Argentinian research base, San Martin, located on one of the Debenham Islands adjacent to the ice cliff. McClary Glacier to the north is a valley glacier with a small accumulation area at approximately $600 \mathrm{~m}$ a.s.l. The outflow of the ice is directed in two opposite directions (Wunderle and Schmidt, 1997). In contrast, Northeast Glacier, to the south of McClary Glacier, is a valley glacier with a total length of about $25 \mathrm{~km}$, fed by an ice stream coming down from the plateau of Palmer Land at approximately $1500 \mathrm{~m}$ a.s.l. Both ice streams are flanked by

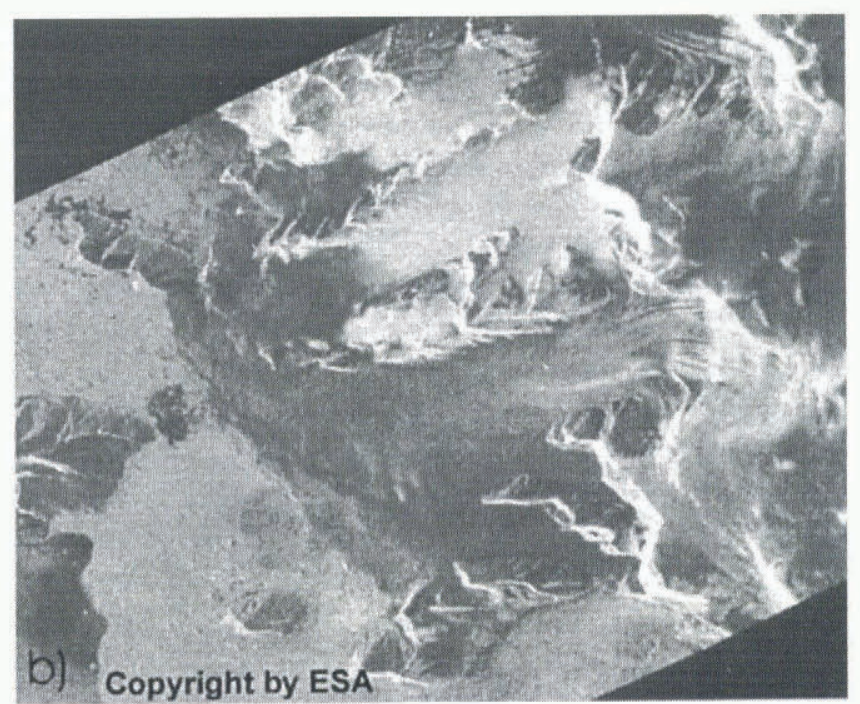

Fig. 2. Map of investigation area and model result (a) and ERS PRI image (b) for 18 January 1995. The upper left corner is located at $67^{\circ} 17^{\prime} 33^{\prime \prime} \mathrm{W}, 68^{\circ} 14^{\prime} 06^{\prime \prime} \mathrm{S}$. (a) The model result illustrates the situation at the time of image acquisition. Contour lines with $100 \mathrm{~m}$ intervals derived from the DTM are overlaid. Discontinuities at contour lines result from merging DTMs with different resolution. The plus signs mark the locations of AWSs. Shaded grey tones represent areas with some liquid-water content leading to reduced backscatter intensities on the SAR image. Only the lightest grey tone stands for areas with absolutely frozen snow and with no liquid-water content at all. (b) ERS-1 PRI image from 18 January 1995, $0200 \mathrm{~h}$ local time covering the same area as (a). The plateau of Palmer Land is partly visible at the eastern margin of the image. The central parts of the image are comprised by McClary Glacier to the north and Northeast Glacier to the south. The mountainous island to the east is Millerand Island. Bright areas on the northwestern parts of McClary Glacier are due to frozen snow interspersed with ice lenses. The low-lying parts of $\mathrm{McClary}$ Glacier and the surface of Northeast Glacier are depicted in dark tones signifying the presence of liquid water in the snow cover. The dry snow on the plateau with small grain-sizes, low snow density and no ice lenses also leads to low backscatter intensity in the SAR image. 
ridges with summits at altitudes of $700-1000 \mathrm{~m}$ a.s.l. Because of the different glacial and topographic features, it is anticiclimate variations.

The mean annual temperature at sea level is $-5.5^{\circ} \mathrm{C}$ but varies by as much as $\pm 4^{\circ} \mathrm{C}$. Mean temperatures in January range from $-1.5^{\circ}$ to $+2.5^{\circ} \mathrm{C}$ (Schwerdtfeger, 1976 ; Reynolds, 1981; Wunderle, 1996b). Compared to other locations on the Antarctic Peninsula, this region obtains more direct solar radiation and less precipitation, because of the sheltered situation with high mountains to the north (Adelaide Island), east (Palmer Land) and south (Alexander Island). Under these climate conditions the equilibrium line of both glaciers is at about sea level, with superimposed ice being exposed occasionally. During summer the lower parts of the glaciers belong to the wet-snow zone, with considerable melting between sea level and approximately $400 \mathrm{~m}$ a.s.l.

\section{DATA}

During two summer field trips, AWSs were operated in the lower area of the glaciers. The systems, supplied by Campbell Scientific (UK), were each equipped with temperature and humidity probes at two levels $(0.8$ and $2.0 \mathrm{~m})$, windspeed and wind-direction instruments, three snow-temperature probes, a net radiometer and two pyranometers to collect data on downward and upward shortwave radiation fluxes. All data were collected as 10 min means. The AWS locations are marked with crosses in Figure 2a. In the 1993-94 summer, only one AWS was operated, at the lowest of the three locations, at $120 \mathrm{~m}$ a.s.l. This AWS collected data from 26 January to 2 March 1994. During the summer of 1994-95, three AWSs were installed from 18 December 1994 to 10 February 1995. Unfortunately, coverage by ERS scenes was poor in 1995, only one scene being available. In 1994, during the 3 day orbit phase of ERS-1, a sequence of three frames was obtained between 1 and 13 February. The images were co-registered and roughly geocoded to the digital terrain model (DTM). The transition from wet snowpack to frozen snow cover was digitised according to the visual appearance in the images. Figure $2 \mathrm{~b}$ gives an example of an ERS image of the areas under investigation. Model results and remote-sensing data were compared using the transitions obtained from the ERS-1 data from 1, 7 and 13 February 1994 and the image from 18 January 1995. pated that the glaciers will react differently to regional

\section{MODEL DESCRIPTION}

Latent- and sensible-heat fluxes were calculated from the meteorological data obtained in 1995 according to the bulk formulations for turbulent-energy fluxes (Brutsaert, 1982). Compensation for the effect of stable stratification in the atmosphere was obtained by using the bulk Richardson number with a formulation provided by Braithwaite (1995). Net radiation was measured directly with a Q-7 instrument supplied by Campbell Scientific (UK). The energy balance obtained for periods with air temperatures above $0^{\circ} \mathrm{C}$ was used to compute ablation. This was compared with snowmelt monitored in snow pits that were dug about twice per week. The correlation coefficient between modelled and measured snowmelt based on 15 data points was $r=0.92$.

To obtain spatial estimates of the status of the snow cover, the energy-balance estimates had to be extrapolated over the entire glacier surface. Multiple regression analysis between temperature, shortwave irradiance, net radiation and energy balance was performed. The best overall result, with a multiple regression coefficient of $r=0.66$, was obtained using means of 6 hour each or four values per day (Table 1). Although net radiation was better than shortwave irradiance in the regression analysis, shortwave irradiance was substituted for it because of the difficulties that arise from trying to model spatially distributed net radiation. Table 1 summarises the results from the regression obtained at the locations of the AWSs. Figure $3 \mathrm{a}$ and $\mathrm{b}$ show the scat-

Table 1. Results from multiple regression analysis between air temperature, shortwave irradiance and radiation budget as independent variables and energy balance as a dependent variable. The analysis was performed using 6 hour means from 1 January to 10 February 1995

\begin{tabular}{lccc}
\hline & $\begin{array}{c}\text { Coefficient of } \\
\text { regression }\end{array}$ & $\begin{array}{c}\text { Explained variance } \\
\text { with radiation } \\
\text { balance }\end{array}$ & $\begin{array}{c}\text { Explained variance } \\
\text { without radiation } \\
\text { balance }\end{array}$ \\
& & $\%$ & $\%$ \\
\hline $\begin{array}{l}\text { Temperature } \\
\begin{array}{l}\text { Irradiance } \\
\text { Radiation balance }\end{array}\end{array}$ & $9.971 \mathrm{~W} \mathrm{~m}^{-2} \mathrm{~K}^{-1}$ & 52 & 52 \\
$\begin{array}{l}\text { Regression constant } \\
\text { Multiple regression } \\
\text { coefficient }\end{array}$ & $3.097 \mathrm{~W} \mathrm{~m}^{-2}$ & 42 & 42 \\
\hline
\end{tabular}

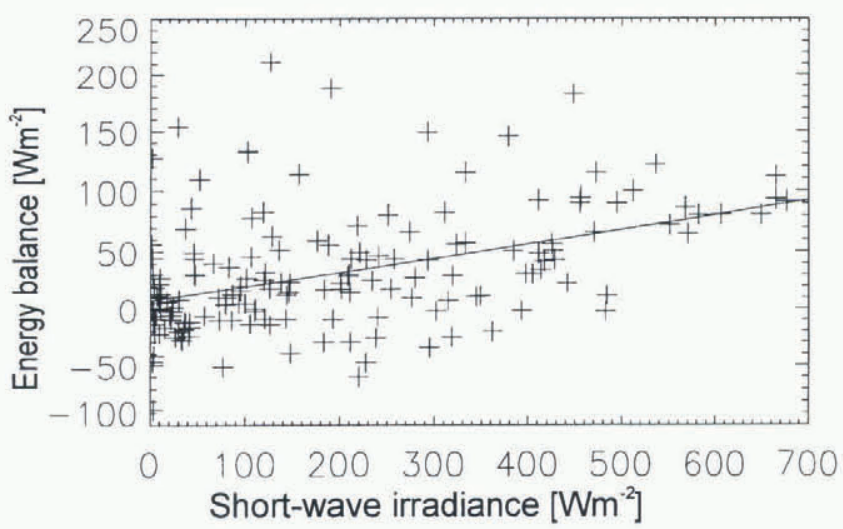

Fig. 3. Correlation between shortwave irradiance and energy balance ( $a)$ and between air temperature and energy balance (b). Each data point represents a 6 hour mean. The time period covers 6 weeks from 1 January to 10 February 1995. Regression coefficients from the multiple regression analysis are listed in Table 1. 
tering of data points for shortwave irradiance and temperature, respectively, in relation to energy-balance estimates. Shortwave irradiance was modelled using the shortwave irradiance model (SWIM) designed by Parlow (1996). This model calculates diffuse and direct insulation on a DTM incorporating a standard atmosphere for polar latitudes, the position of the sun, and the sky-view factor for each pixel. The computed shortwave irradiance for each step in time was compared with the recordings at the AWSs. The model was calibrated using days with a clear blue sky (Fig. 4). Factors for direct and diffuse radiation had to be set to 1.19 in order to reproduce AWS data correctly with the model. Then the effect of cloudiness was taken into account. The ratio between AWS readings and the model results at the specific gridpoint was used to change factors again for direct and diffuse radiation, assuming that the direct radiation would be cut off by clouds more effectively than diffuse radiation. Model and AWS measurements correlated best using

$$
\begin{aligned}
& \mathrm{d} f=\mathrm{d} f_{0} r^{1.3} \\
& \mathrm{~d} r=\mathrm{d} r_{0} r^{0.5}
\end{aligned}
$$

where $\mathrm{d} f_{0}$ is the multiplier for diffuse and $\mathrm{d} r_{0}$ the multiplier for direct radiation under clear sky, $\mathrm{d} f$ and $\mathrm{d} r$ are the multipliers for cloudy sky, and $r$ denotes the ratio between actual recording at the AWS and modelled radiation assuming clear sky. Using a lapse rate of $0.65^{\circ} \mathrm{C}\left(100 \mathrm{~m}^{-1}\right)$, temperature was extrapolated spatially on the basis of the DTM. With the data layers of shortwave irradiance and temperature, it was possible to estimate the energy balance for the entire glaciers using the regression coefficients, which were obtained from the AWS data (Table 1).

The snowpack in the area of examination was characterised by snow grains of approximately $1-3 \mathrm{~mm}$ diameter, about five to ten ice lenses in the uppermost metre of snow and a snow density of $0.4-0.5 \mathrm{~kg} \mathrm{~m}^{-3}$. These characteristics permit microwave radiation from the ERS to penetrate the snowpack to about $0.8 \mathrm{~m}$ under the assumption that there is a minimum liquid-water content of $0.5 \%$ (Schneider and others, 1997). It was found from measurements in snow pits that, during a 6 hour period, changes in the atmospheric boundary layer are propagated down into the snowpack to

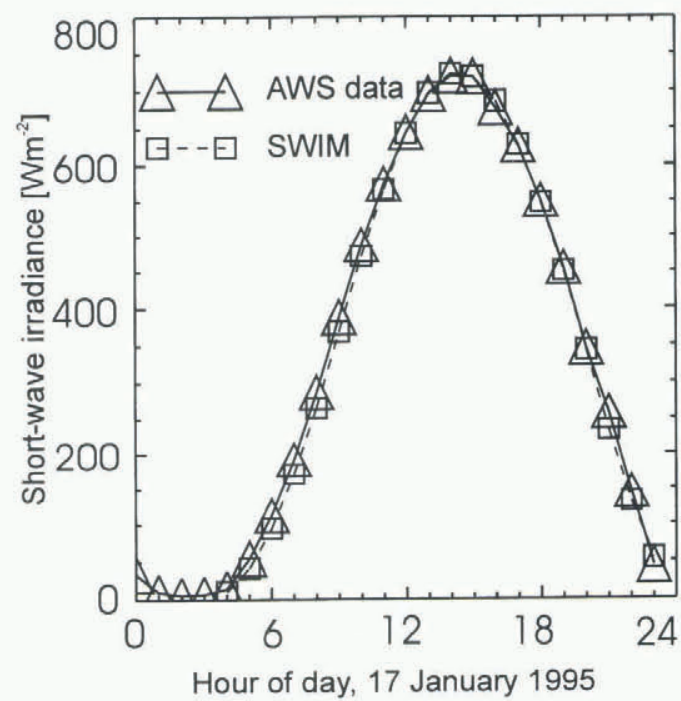

Fig. 4. Measured and modelled shortwave irradiance for a clear day (17 January 1995). In order to compensate for the local atmospheric conditions, multipliers for diffuse and direct irradiance had to be set to 1.19 in relation to the standard High Arctic atmosphere, which is incorporated into SWIM.

about $0.1 \mathrm{~m}$. Based on this information, a simple snow-cover model with eight layers was designed to separate wet and frozen snowpack. For each time interval with a positive energy balance and air temperature above $0^{\circ} \mathrm{C}$, the number of wet layers at each gridpoint in the DTM was incremented by one. When both parameters were negative, the number of wet layers was reduced by one. In all other cases no change was applied to the gridpoints in the model. Since ERS receives information from the uppermost metre of the snowpack only, "wet" in this special sense is defined as at least one layer in the model still containing some liquid water, and "frozen" is defined as all eight layers being completely frozen. The complete structure of the combined energy-balance and snow-cover model is illustrated as a block diagram in Figure 5. The result from the model for the time of the satellite-image acquisition was compared with what was found in the remotesensing data at the same time by extracting the average altitudes of the transition line in both datasets (Fig. 6).

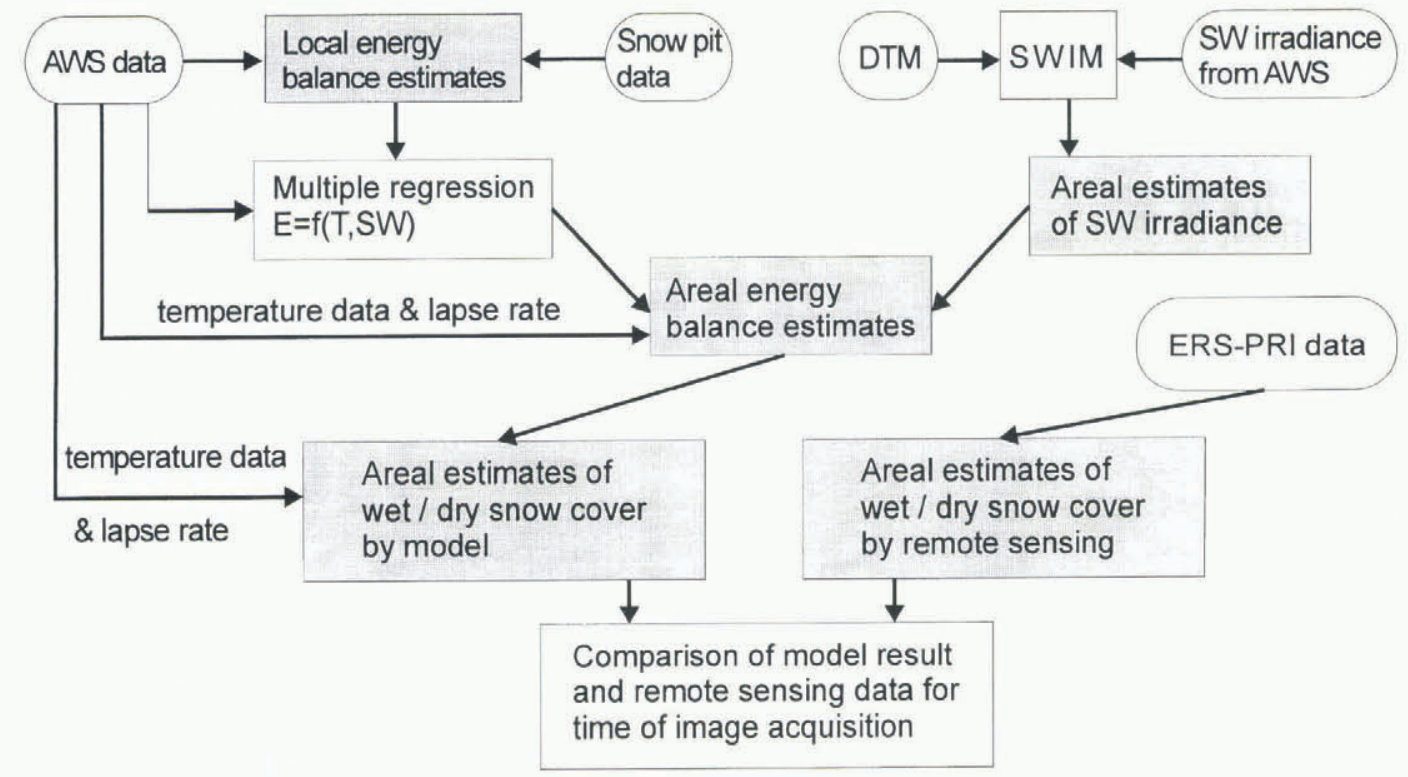

Fig. 5. Block diagram to illustrate the model scheme. Primary data are shown in rounded frames. Results are shown in rectangles with grey background. 


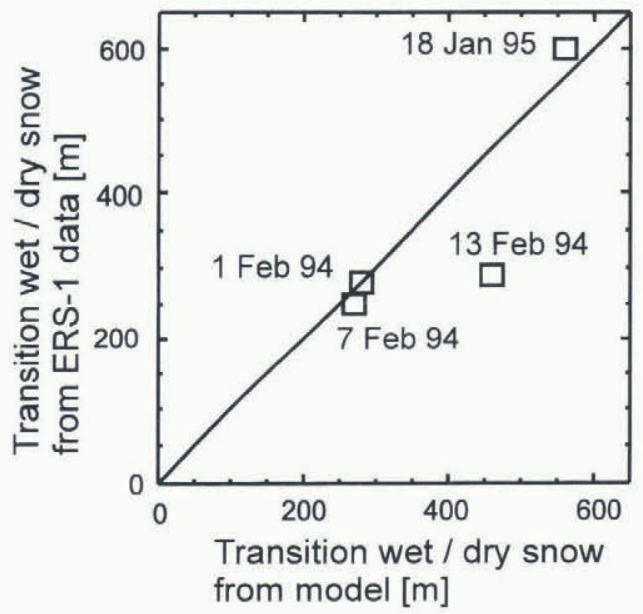

Fig. 6. Average altitude (a.s.l.) of transition from wet to dry snow modelled ( $x$ axis) and derived from ERS PRI images (y axis). Due to the small number of ERS frames available, a calculation of correlation was not performed.

\section{DISGUSSION AND CONGLUSIONS}

As can be seen in Figure 6, the model results and remotely sensed information are in good agreement for three of the four images available. The model result for 13 February 1994, where areal extent of wet snow is overestimated, may be due to a short period of extremely high air temperatures shortly before the time of image acquisition. The model reacts very promptly to wetting of the surface. However, it could be that the memory effect of the snow cover was overestimated. We assume that the rate of refreezing of the snow cover was larger than that estimated by the model.

A major drawback is the fact that only four images were available in the time slots covered by the field measurements. Further analysis of the capabilities and limitations of this method could only be performed using more images to check against the model. Since atmospheric conditions change within a matter of hours, it would be necessary to obtain one image per day to establish this method firmly. Further research must also concentrate on a more physicsbased snow-cover model, because at this stage the model includes many simplifications, and it cannot allow for all the complicated processes associated with melting and refreezing in the snowpack. Since the derivation of spatially distributed energy-balance estimates relies on a statistical approach, it may be difficult to use the model as it stands at other locations along the Antarctic Peninsula. To use this approach at different locations in order to go one step further towards regional climate monitoring, it would be necessary to establish the statistical parameters of the multiple regression analysis locally for each investigation area. Snowpack parameters such as snow density and grain-size must also be known in some detail in order to interpret unambiguously the backscatter intensities in the SAR image with respect to wetness. Despite the limitations discussed, it is obvious that spatial estimates derived from meteorological recordings of temperature and shortwave irradiance are sufficient to reproduce roughly what can be observed in the SAR imagery. With this knowledge, SAR imagery can be employed in the inverse sense to estimate local meteorological conditions, not only at one location, but spatially for a whole area in snow-covered regions, as long as parts of the surface are melting for at least some of the summer season.

\section{ACKNOWLEDGEMENTS}

This research was supported by the German Secretary of Science and Research (BMBF) within the programme "Dynamic Processes in Antarctic Geosystems" (DYPAG; contract No. 03PL016A), and by the European Space Agency pilot study "Monitoring of Dynamic Processes in Antarctic Geosystems" (MODPAG; contract No. AO2.D149). I would like to thank the Instituto Antarctico Argentino, the British Antarctic Survey and the AlfredWegener-Institut für Polar- und Meeresforschung for their support in respect to logistics and field equipment. I am grateful for the invaluable assistance of, and discussions in the field with, the Argentinian and German collaborators. I wish to thank S. Wunderle for making available field data and remote-sensing data from the 1993-94 summer campaign, and K. Jacka and T. Gibson of the Antarctic Cooperative Research Center, University of Tasmania, for their helpful comments on the paper.

\section{REFERENCES}

Braithwaite, R.J. 1995. Aerodynamic stability and turbulent sensible-heat flux over a melting ice surface, the Greenland ice sheet. 7. Glaciol., $41(139), 562-571$.

Brutsaert, W. H. 1982. Evaporation into the atmosphere. Dordrecht, Reidel.

Morris, E. M. and D. G. Vaughan. 1992. Snow surface temperatures in West Antarctica. In Morris, E. M., ed. The contribution of Antarctic Peninsula ice to sea level rise. Cambridge, British Antarctic Survey, 17-24. (Ice and Climate Special Report 1.

Parlow, E. 1996. Correction of terrain illumination effects in satellite data. In Parlow, E., ed. Progress in environmental remote sensing research and applications. Rotterdam, A. A. Balkema, 139-145.

Paterson, W. S. B. 1994. The physics of glaciers. Third edition. Oxford, etc., Elsevier.

Peel, D. A. 1992. Ice core evidence from the Antarctic Peninsula region. In Bradley, R. S. and P. D. Jones, eds. Climate since A.D. 1500. London and New York, Routledge, 549-571.

Reynolds, J. M. 1981. The distribution of mean annual temperatures in the Antarctic Peninsula. Br. Antarct. Surv. Bull. 54, 123-133.

Schlesinger, M. E. 1993. Model projections of $\mathrm{CO}_{2}$-induced equilibrium climate change. In Warrick, R. A., E. M. Barrow and T. M. L. Wigley, eds. Climate and sea level change: observations, projections and implications. Cambridge, Cambridge University Press, 169-191.

Schneider, C., S. Wunderle and M. Friedrich. 1997. Snow cover investigations by means of ground truth, modelling and ERS-SAR imagery. In EARSeL SIG Workshop in Land Ice and Snow, 17-18 April 1997, Freiburg. Proceedings. Paris, European Association of Remote Sensing Laboratories, 95-102.

Schwerdtfeger, W. 1976. Changes of temperature field and ice conditions in the area of the Antarctic Peninsula. Mon. Weather Rev., 104, 1441-1443.

Smith, R. C., S. E. Stammerjohn and K. S. Baker. 1996. Surface air temperature variations in the western Antarctic Peninsula region. In Ross, R. M., E. E. Hofmann and L. B. Quentin, eds. Foundations for ecological research west of the Antarctic Peninsula. Washington, DC, American Geophysical Union, 105-121. (Antarctic Research Series 70.)

Ulaby, F. T., R. K. Moore and A. K. Fung. 1982. Microwave remote sensing, active and passive. Vol. 2. Radar remote sensing and surface scattering and emission theory. Reading, MA, Addison-Wesley Publishing Co.

Vaughan, D. G. and C. S. M. Doake. 1996. Recent atmospheric warming and retreat of ice shelves on the Antarctic Peninsula. Nature, 379 (6563), 328-331.

Wunderle, S. 1996a. A comparison between the dry snow lines derived from meteorological data and ERS-1 SAR images on the Antarctic Peninsula. In Parlow, E., ed. Progress in environmental remote sensing research and applications. Rotterdam, A. A. Balkema, 249-252.

Wunderle, S. 1996b. Die Schneedeckendynamik der Antarktischen Halbinsel und ihre Erfassung mit aktiven und passiven Fernerkundungsverfahren. Freibg. Geogr. Hefte 48.

Wunderle, S. andJ. Schmidt. 1997. Comparison of interferograms using different DTMs - a case study of the Antarctic Peninsula. In EARSeL SIG Workshop in Remote Sensing of Land Ice and Snow, 17-18 April 1997, Freiburg. Proceedings. Paris, European Association of Remote Sensing Laboratories, 131-135. 